REVIEW

\title{
Probiotics and human health: a clinical perspective
}

\author{
H S Gill, F Guarner
}

Postgrad Med J 2004;80:516-526. doi: 10.1136/pgmj.2003.008664

There is unequivocal evidence that administration of probiotics could be effective in the treatment of acute infectious diarrhoea in children and the prevention of antibiotic associated diarrhoea and nosocomial/ community acquired diarrhoea. Encouraging evidence is also emerging for the effectiveness of probiotics in the prevention and management of pouchitis and paediatric atopic diseases, and the prevention of postoperative infections. There is also strong evidence that certain probiotic strains are able to enhance immune function, especially in subjects with less than adequate immune function such as the elderly. Efficacy of probiotics in the prevention of traveller's diarrhoea, sepsis associated with severe acute pancreatitis, and cancers, the management of ulcerative colitis, and lowering of blood cholesterol remains unproven. In addition to firm evidence of efficacy (for a range of conditions), major gaps exist in our knowledge regarding the mechanisms by which probiotics modulate various physiological functions and the optimum dose, frequency, and duration of treatment for different probiotic strains.

See end of article for authors' affiliations

Correspondence to: Professor Harsharnjit S Gill, Primary Industries Research Victoria-

Werribee Centre, Department of Primary Industries, 600 Sneydes Road, Werribee, VIC 3030, Australia; harsharn. gill@dpi.vic.gov.au

Submitted

27 November 2003

Accepted

26 February 2004
$\mathrm{T}$ he human gastrointestinal tract is home to diverse and vast communities of microorganisms representing over 400 cultivable species. The colonisation of the gastrointestinal tract begins immediately after birth. The mode of delivery, use of antibiotics, and the level of hygiene are known to exert a significant influence on the number and species of microorganisms that colonise the gut. At first Escherichia coli and streptococcus dominates, but in breast fed infants the number of bifidobacteria increases while those of $E$ coli, streptococcus, and clostridia decreases. ${ }^{1}$ A change to the adult flora occurs after weaning and by the second year of life the intestinal flora becomes similar to that of an adult ${ }^{2}$ and remains relatively stable throughout life. The density and diversity of microbes increases progressively from stomach $\left(10^{2-3}\right.$ colony forming units (cfu)/g lumenal contents) to colon $\left(10^{1-12} \mathrm{cfu} / \mathrm{g}\right.$ lumenal contents). In a healthy adult, the gastrointestinal tract contains 10 times as many bacteria ( $10^{14}$ bacteria) as eukaryotic cells in the entire body ${ }^{1}$; the combined genome of the intestinal flora is estimated to be 50-100 times the size of the human genome. ${ }^{3}$ As these organisms are metabolically active and interact continuously with their environment (including other bacteria, the gut epithelium, mucosal immune system, the central nervous system, and the endocrine system), they are able to exert a significant influence on the postnatal development and the host physiology ${ }^{4}$; the metabolic activity of microflora is considered to be equal to that of liver. ${ }^{5}$

While a majority of the indigenous flora are benign or exhibit health promoting properties, some possess the potential to cause disease. For example, bifidobacteria and lactobacilli are associated with health, while clostridia are considered detrimental to health. Normally, a balance exists between pro-health and anti-health organisms. However, when this delicate ecological balance is perturbed by environmental or physiological factors, predisposition to infectious and immunoinflammatory diseases is enhanced. Research over the past two decades has provided evidence that administration of probiotics could be used to optimise gut flora and to prevent and treat a range of diseases. Probiotics are defined as live micro-organisms which when administered in adequate amounts confer a health benefit on the host. Bifidobacteria and lactobacilli are commonly used as probiotics. Consumption of specific strains of probiotics is associated with a range of health benefits, ${ }^{6}$ although strong scientific evidence exists only for a small number of conditions. The health benefits supported by adequate clinical data or promising animal data include prevention and treatment of diarrhoeal disease (acute infantile diarrhoea, antibiotic associated diarrhoea, nosocomial infections), prevention of systemic infections, management of inflammatory bowel disease, immunomodulation, prevention and treatment of allergies, anticancer effects, treatment of cholesterolaemia, and alleviation of lactose intolerance.

Probiotics are defined as live micro-organisms which when administered in adequate amounts confer a health benefit on the host.

\section{PREVENTION AND TREATMENT OF DIARRHOEAL DISEASE}

A number of clinical trials have tested the efficacy of probiotics in the prevention of acute diarrhoeal conditions. ${ }^{7}$ Diarrhoea is the most frequent side effect of both the short and long term use of antibiotics, particularly during

Abbreviations: cfu, colony forming units; IL, interleukin; NK, natural killer (cells); SCORAD, SCORing Atopic Dermatitis (score); TNF- $\alpha$, tumour necrosis factor- $\alpha$ 


\section{Box 1: Gut flora}

- Human gut contains 10 times more bacteria $\left(10^{14}\right)$ than eukaryotic cells in the entire human body.

- The total genes of the gut flora is estimated to be 50100 times the size of the human genome.

- The metabolic activity of the intestinal flora is considered to be equal to liver.

multiple antibiotic regimens. Coadministration of probiotics to patients on antibiotic therapy has been shown to reduce the incidence of antibiotic associated diarrhoea in children and in adults. In placebo controlled studies, diarrhoea occurred at a rate of $15 \%$ to $26 \%$ in the placebo arms but only in $3 \%$ to $7 \%$ of patients receiving a probiotic. Different strains have been tested including Lactobacillus rhamnosus strain GG, Lactobacillus acidophilus, Lactobacillus bulgaricus, and the yeast Saccharomyces boulardii. Two meta-analyses concluded that probiotics could be used to prevent antibiotic associated diarrhoea. ${ }^{8} 9$

Nosocomial diarrhoea is a major problem in paediatric hospitals worldwide. Prophylactic use of probiotics has proven useful for the prevention of acute diarrhoea in infants admitted into the hospital ward for a chronic disease condition. In a double blind, placebo controlled trial, Saavedra and coworkers showed that supplementation of an infant formula with Bifidobacterium bifidum and Streptococcus thermophilus reduced the incidence of diarrhoea $(7 \% \quad v 31 \%)$ and rotavirus shedding (10\% $v 39 \%)$ in hospitalised infants aged 5-24 months. ${ }^{10}$ In another placebo controlled double blind study, oral administration of $L$ rhamnosus strain GG to infants (1-36 months old), hospitalised for reasons other than diarrhoea, reduced the risk of nosocomial diarrhoea $(6.7 \% \vee 33.3 \%)$ and rotavirus gastroenteritis $(2.2 \% \vee 16.7 \%) .{ }^{11}$ Prevalence of rotavirus infection was not influenced by probiotic treatment but the risk of symptomatic rotavirus enteritis was significantly reduced. A third published clinical trial on nosocomial diarrhoea in infants (1-18 months old) showed no statistically significant benefit of Lactobacillus GG intake, ${ }^{12}$ but the rate of symptomatic rotavirus enteritis in the probiotic arm (13.2\%) was found to be lower than in the placebo arm $(20.8 \%)$.

Probiotics may also be useful in the prevention of community acquired diarrhoea. The study by Oberhelman and coworkers ${ }^{13}$ included 204 infants (6-24 months old) from an indigent periurban town who were followed up over a 15 month period. Significantly fewer episodes of diarrhoea per child per year were observed in children given Lactobacillus $G G$ supplemented gelatin than in the placebo (control) group. In a multicentre, randomised, double blind trial, ${ }^{14}$ conducted over four months with 928 healthy children aged 6-24 months, the incidence of acute diarrhoea was significantly reduced by supplementation with Lactobacillus casei fermented milk ( $15.9 \%$ ) as compared with yogurt (22\%). Several studies have investigated the efficacy of probiotics in the prevention of travellers' diarrhoea in adults, but methodological deficiencies, such as low compliance with the treatment and problems with the follow up, limit the validity of their conclusions. ${ }^{15}$

The benefit of probiotics as a treatment for acute diarrhoea in children has also been demonstrated. Probiotics such as Lactobacillus reuteri, Lactobacillus GG, L casei, and $S$ boulardii have proven useful in reducing the duration of acute diarrhoea in controlled clinical trials. Three meta-analyses of controlled clinical trials have been published. ${ }^{16-18}$ The results of the systematic reviews are consistent and suggest that probiotics are safe and effective. Probiotic therapy shortens the duration of acute diarrhoeal illness in children by approximately one day.

\section{TREATMENT OF HELICOBACTER PYLORI INFECTION}

Probiotics have been tested as a new strategy for eradication of Helicobacter pylori infection of the gastric mucosa in humans. Some strains of lactic acid bacteria are known to inhibit the growth of $H$ pylori in vitro. However, administration of a probiotic-containing yogurt was found to be ineffective in the eradication of $H$ pylori infection in 27 subjects. ${ }^{19}$ Two studies that examined the use of probiotics as a supplement to the classical triple therapy with antibiotics also failed to demonstrate any beneficial effect of probiotic therapy (see Sheu et $\mathrm{l}^{20}$ ). In contrast, in a non-blinded trial, the triple therapy plus yogurt resulted in a higher $H$ pylori eradication rate than the triple therapy only $(91 \% \vee 78 \%)$ by intention-to-treat analysis. ${ }^{20}$ It is important to note, however, that $H$ pylori eradication rates were similar for both groups of patients $(93.5 \% \vee 89 \%$, not significant) by per protocol analysis-that is, when considering only the patients that completed the seven day antibiotic therapy. Interestingly, a lower number of dropout events were observed in the yogurt group. Since the trial was not blind, the consistency of this observation needs to be confirmed.

\section{Mechanisms of action}

Several mechanisms (producing antimicrobial substances, stimulating mucus secretion, strengthening gut barrier function, competing for adhesion sites, stimulating specific and non-specific immune responses, etc) by which probiotics mediate their anti-infection effects have been suggested. ${ }^{21}$ However, the relative importance of these mechanisms remains unknown.

\section{PREVENTION OF SYSTEMIC INFECTIONS}

Translocation of viable or dead bacteria in minute amounts constitutes a physiologically important boost to the immune system. However, dysfunction of the gut mucosal barrier may result in the passage of large quantities of viable microorganisms, usually belonging to Gram negative aerobic genera, which can disseminate throughout the body producing sepsis. Bacterial translocation and its complications have been shown to occur in several pathological conditions such as postoperative sepsis, severe acute pancreatitis, advanced liver cirrhosis, multisystem organ failure, etc. ${ }^{22}$

Probiotics have been used to prevent sepsis in patients with severe acute pancreatitis. In a randomised double blind trial, patients were treated with either Lactobacillus plantarum or placebo. Incidence of infected pancreatic necrosis and abscesses were observed at a significantly lower rate in $L$ plantarum treated patients than in the control group. ${ }^{23}$

A randomised study involving 95 liver transplant patients compared the incidence of infections among three groups of patients submitted to different prophylaxis procedures: selective bowel decontamination with antibiotics, administration of live $L$ plantarum with fermentable fibre, and administration of heat killed $L$ plantarum plus the fibre supplement. Postoperative infections were recorded in 15 out of 32 patients $(48 \%)$ in the antibiotics group, four out of 31 ( $13 \%)$ in the live L plantarum group, and 11 out of $32(34 \%)$ in the heat killed $L$ plantarum group, being significant the difference between antibiotics and live $L$ plantarum groups. ${ }^{24}$ In a second study with liver transplant patients recently concluded by the same group in Berlin, patients were randomised to receive a synbiotic preparation (including four probiotic strains: Pediococcus pentoseceus, Leuconostoc mesenteroides, Lactobacillus paracasei, and L plantarum and four fermentable fibres: $\beta$-glucan, inulin, pectin, and resistant 
starch) or a placebo consisting of the four fibres only. Postoperative infection occurred in only one patient in the treatment group $(n=33)$, in contrast to 17 out of 33 in the placebo group. ${ }^{25}$ Early administration of live probiotics may become a useful and effective therapeutic alternative to prevent postoperative infections, as opposed to prophylaxis with antibiotics.

\section{Management of inflammatory bowel diseases}

Crohn's disease, ulcerative colitis, and pouchitis are chronic conditions of unknown aetiology. Evidence suggests that abnormal activation of the mucosal immune system against the enteric flora is the key event triggering inflammatory mechanisms, that induce mucosal injury and perpetuate intestinal lesions to chronicity. Patients show an increased mucosal secretion of IgG antibodies against commensal bacteria, ${ }^{26}$ and mucosal T-lymphocytes are hyper-reactive against antigens of the common flora, suggesting that local tolerance mechanisms are abrogated. ${ }^{27}$ In Crohn's disease, faecal stream diversion has been shown to prevent recurrence of mucosal lesions, whereas infusion of intestinal contents activated the lesions. ${ }^{28}$ In ulcerative colitis, treatment with an enteric coated preparation of broad spectrum antibiotics reduced metabolic activity of the flora and mucosal inflammation. ${ }^{29}$

Experimental studies based on co-culture of non-pathogenic bacteria with human intestinal mucosa have shown that different bacteria elicit different types of cytokine response. In Crohn's disease, a commensal $E$ coli strain stimulates the release of tumour necrosis factor- $\alpha$ (TNF- $\alpha$ ) and interleukin (IL)- 8 by the inflamed mucosa. ${ }^{30}$ However, some lactobacillus strains including $L$ casei downregulate the spontaneous release of TNF- $\alpha$ by inflamed tissue, and also the inflammatory response induced by $E$ coli. ${ }^{30}{ }^{31}$ The antiinflammatory effect of $L$ casei is transduced to the underlying tissue and results in reduced expression of activation markers by lamina propria T-lymphocytes, ${ }^{30}$ suggesting that signals generated at the mucosal surface can promote changes in the phenotype of lamina propria lymphocytes. A balanced local microecology could restore immune homoeostasis in Crohn's disease.

Probiotics have been tested in animal models of bowel inflammation. Mice deficient of the IL-10 gene spontaneously develop colitis. Oral administration of either VSL\#3, a mixture of eight bacteria strains, or $L$ plantarum significantly decreased histological colitis score in this animal model. ${ }^{32}{ }^{33}$ However, the same $L$ plantarum strain failed to reduce the severity of colitis in the TNBS model in the rat. ${ }^{34} \mathrm{~A}$ bacterium genetically engineered to secrete the anti-inflammatory cytokine IL-10 prevented the onset of colitis in the IL10 knockout mouse model..$^{35}$ The prebiotic inulin increases counts of lactobacilli and bifidobacteria in the colonic lumen. The effect of inulin was tested in the rat model of distal colitis induced by dextran sodium sulphate, a model that resembles human ulcerative colitis. ${ }^{36}$ Oral inulin prevented mucosal inflammation, as evidenced by lower colonic lesion scores, lower release of inflammatory mediators, and lower tissue myeloperoxidase activity in test rats as compared with controls.

In ulcerative colitis, two randomised controlled trials investigated the effectiveness of an orally administered enteric coated preparation of viable $E$ coli strain Nissle 1917 as compared with mesalazine, the standard treatment for maintenance of remission. ${ }^{37}{ }^{38}$ These two studies concluded that the non-pathogenic $E$ coli strain has an equivalent effect to mesalazine in maintaining remission. The same probiotic product was tested for efficacy in maintaining remission in 28 patients with colonic Crohn's disease. ${ }^{39}$ This placebo controlled study showed a lower rate of relapse (33\% v 63\%) in the probiotic group than in controls.

The VSL\#3 mixture mentioned above has proven highly effective for maintenance of remission of chronic relapsing pouchitis, after induction of remission with antibiotics. ${ }^{40}$ In this study, a relapse occurred in only three out of 20 patients of the VSL\#3 group and in all the 20 patients of the placebo group. Of interest, all patients on remission in the probiotic arm had relapses within four months after stopping treatment at conclusion of the trial. Treatment with VSL\#3 is also effective in the prevention of the onset of pouchitis after ileal pouch-anal anastomosis. ${ }^{41}$ Results of a controlled trial published in abstract form suggest that VSL\#3 is better than mesalazine in the prevention of postoperative recurrence of Crohn's disease at one year. ${ }^{42}$

The efficacy of Lactobacillus $G G$ in postoperative recurrence of Crohn's disease has been tested in a randomised, double blind trial. The probiotic showed no effect in the prevention of clinical and endoscopic recurrence as compared with placebo. ${ }^{43}$ Lactobacillus $G G$ also had no effect, as a primary therapy, on clinical or endoscopic responses in patients with chronic pouchitis. ${ }^{44}$ Another study included 32 patients with quiescent Crohn's disease and tested $S$ boulardii for maintenance of remission as a coadjuvant therapy added to standard mesalazine. Clinical relapse rate was higher in the group treated with mesalazine alone..$^{45}$ Finally, the prebiotic inulin has been tested in patients with an ileal pouch-anal anastomosis. Compared with placebo, three weeks of dietary supplementation with inulin reduced endoscopic and histological parameters of inflammation of the mucosa of the ileal reservoir. ${ }^{46}$ The effect was associated with an increase in faecal butyrate and a decrease in bacteroides counts.

Although initial open label studies showed promising prospects, with the exception of the studies on pouchitis, published results of controlled clinical trials in patients with inflammatory bowel diseases are poor (see Tamboli for an extensive review of published trials ${ }^{47}$ ). We need further research on mechanisms of action in order to optimise the use of probiotics or prebiotics for these indications.

\section{PREVENTION AND TREATMENT OF ATOPIC DISEASES}

Atopic diseases (for example, atopic dermatitis, allergic rhinitis, and asthma) represent an exaggerated and imbalanced immune response to environmental or food allergens. Recent studies have shown that prevalence of allergic diseases in western societies is increasing at an alarming rate whereas the frequency of allergic diseases is much lower in developing countries. It has been suggested that this may be the result of reduced microbial pressure ${ }^{48}$ or exposure to inappropriate microbial stimulus (including overt infections) during infancy and early childhood in industrialised countries due to improved hygienic conditions. Appropriate microbial stimulus during early age is believed to be essential to counterbalance the skewed Th2 immune phenotype of the newborn and the maturation of the immune system to a nonatopic state (education of the developing immune system). Differences in the composition of microflora of infants with a high and a low prevalence of allergy, ${ }^{49}$ and in infants in whom allergy was and was not developing ${ }^{50}$ support this hypothesis. The balance between bifidobacteria and clostridia appears to be the key factor in determining predisposition to allergies. Lower incidence of allergies in breast fed infants, compared with formula fed infants, is associated with higher counts of bifidobacteria in their flora; formula fed infants are known to have more clostridia. Several epidemiological and experimental studies have indicated that stimulation of the immune system by certain microbes or microbial products 
may be effective in the prevention and management of allergic diseases. ${ }^{51}$

\section{Probiotics and the prevention of allergic diseases}

The effectiveness of probiotic therapy in the prevention of allergic diseases has been demonstrated in two randomised controlled trials. Lodinova-Zadnikova et al investigated the preventive efficacy of at birth colonisation with a probiotic (non-enteropathogenic) $E$ coli..$^{52}$ The incidence of allergies was assessed using a questionnaire both after 20 years (150 full term) and 10 years (77 preterm infants) after colonisation. Subjects colonised with $E$ coli were found to have significantly lower incidence of allergies, compared with the control subjects, both after 10 and 20 years. In the second randomised, double blind, placebo controlled study, Kalliomaki et al demonstrated the effectiveness of Lactobacillus $G G$ in the prevention of early atopic disease in children at high risk. ${ }^{53}$ Lactobacillus $G G$ supplementation prenatally to mothers (for two weeks) with a family history of atopy and postnatally to their infants for six months significantly reduced the incidence of atopic eczema $(p=0.008)$ during the first two years life, compared with the placebo group. The frequency of atopic eczema in the probiotic supplemented group (15 of 64, 23\%) was half that of the placebo group ( 31 of $68,46 \%$ ). Re-examination of the cohort at the age of 4 years has further shown that the preventive effect of Lactobacillus $G G$ on atopic eczema extends beyond infancy ${ }^{54} ; 14$ of 53 children receiving Lactobacillus $G G$ had developed atopic eczema, compared with 25 of 54 receiving placebo (relative risk $0.57,95 \%$ confidence interval 0.33 to 0.97 ). Interestingly, however, supplementation had no effect on skin prick test and the induction of IgE (as measured by in vitro IgE test). This may suggest that probiotic therapy does not protect against IgE mediated sensitisation. ${ }^{51}$

\section{Probiotics and the management of allergic diseases}

The ability of bacterial therapy to reduce the symptoms of food allergy was first highlighted by Loskutova ${ }^{55}$ and Ciprandi et al. ${ }^{56}$ Since then, several well designed studies have provided evidence that supplementation with specific strains of probiotics could be effective in the management of atopic disorders.

Majamaa and Isolauri examined the efficacy of extensively hydrolysed whey formula supplemented with Lactobacillus $G G$ in infants with atopic eczema and cows' milk allergy. ${ }^{57}$ In a randomised, double blind, placebo controlled trial, subjects receiving formula with Lactobacillus $G G(\mathrm{n}=13)$ showed significant improvement in clinical symptoms (SCORing Atopic Dermatitis (SCORAD) score) and markers of intestinal inflammation (indicated by significant decreases in the concentrations of faecal $\alpha$-antitrypsin and TNF- $\alpha$ ) compared with the placebo group given formula without probiotics $(n=14)$. Similar effects of probiotic therapy were reported in another randomised, double blind, placebo controlled study by the same authors ${ }^{58}$ in which breast fed infants $(n=27)$ with atopic eczema were weaned onto an extensively hydrolysed whey formula containing Lactobacillus $G G$ or Bbl2 or without probiotics. After two months, infants receiving whey formula with probiotics showed significant improvements in the extent and severity of atopic eczema (SCORAD score: 0 for Lactobacillus GG, 1 for $\mathrm{Bb} 12$ and 13 for placebo group) and reduction in inflammatory responses (as indicated by reductions in the concentration of soluble CD4 in serum and eosinophilic protein $\mathrm{X}$ in urine) compared with the placebo groups. ${ }^{58}$ Expression of cell surface receptors and the production of chemotactic factors remained unchanged. These findings have also been recently confirmed by Rosenfeldt et al..$^{59}$ In a randomised, double blind, placebo controlled crossover study, $56 \%$ of atopic children (to 13 years old) receiving L rhamnosus 19070-2 and L reutri DSM 122460 for six weeks showed improvement of the eczema compared with only $15 \%$ in the placebo group; during the active treatment the extent of eczema decreased from a mean of $18.2 \%$ to $13.7 \%(p=0.02)$. However, the total SCORAD index showed no significant change. Interestingly, the treatment response was more pronounced in subjects with raised IgE levels and a positive skin prick test response. From these studies, it could be concluded that specific probiotic strains might be effective in the management of allergies. Effectiveness of viable but not heat inactivated probiotics in the management of atopic eczema and cows' milk allergy ${ }^{60}$ and an association between the consumption of fermented milk products and a decrease in allergic symptoms has also been reported. ${ }^{61}$

However, little is known about the efficacy of probiotics in preventing allergic disorders in other age groups. Helin et al examined the effect of probiotic supplementation in young adults or teenagers with birch pollen or apple allergy. ${ }^{62}$ Lactobacillus GG therapy for 5.5 months (before, during, and after the pollen birch season) failed to mitigate the symptoms of allergy or reduce the use of medicine. No benefits were noted in subjects exposed to apple challenge test. In another double blind crossover study involving 15 adults with moderate asthma, supplementation with yoghurt with live $L$ acidophilus or yoghurt with $L$ acidophilus for one month was found to have no beneficial effect on spirometric function. ${ }^{63}$

In addition to the induction of regulatory $\mathrm{T}(\mathrm{Tr})$ cells and counter-regulation by Thl cells, ${ }^{64}$ reduced immunogenicity of potential allergens through modification of their structure, ${ }^{65}$ strengthening of the mucosal defences (production of IgA), stabilisation of gut mucosal barrier and downregulation of inflammatory responses ${ }^{66}$ by lactic acid bacteria has been suggested to contribute to antiallergy effects of probiotics. It was also reported that the beneficial effects of Lactobacillus $G G$ were associated with increases in transforming growth factor- $\beta{ }^{67}{ }^{67}$ induction of IL-10 production ${ }^{68}$ and regulation of phagocytic cell function. ${ }^{6}$

Probiotic consumption has been shown to downregulate over expressed immune responses in subjects with autoimmune/ immunoinflammatory disorders (for example, inflammatory bowel disease, atopic disorders) and to enhance specific aspects of immune function in healthy subjects.

\section{ENHANCEMENT OF SPECIFIC PARAMETERS OF IMMUNE FUNCTION}

The immune system employs non-specific and acquired immune mechanisms to mediate protection against pathogenic organisms and the development and metastasis of cancers; deficiencies or dysregulation of the immune system are associated with enhanced disease susceptibility. The nonspecific immune responses constitute the first line of host defence and operate non-selectively against foreign antigens/ substances. The major cellular effectors of innate immune system include phagocytic cells (monocytes, macrophages, and polymorphonuclear cells,), and natural killer (NK) cells. Phagocytic cells play a major role in limiting the spread of infectious challenge, whereas NK cells are critical for controlling viral infections and cancers. The humoral components of the innate immune system include complement, acute phase proteins and cytokines (for example, interferons). In addition, innate immune responses have an 
important role in initiating and regulating the acquired immune responses.

The acquired immunity involves T-lymphocytes and Blymphocytes. B-cells secrete immunoglobulins/specific antibodies, while $\mathrm{T}$-cells provide help for $\mathrm{B}$-cells to produce specific antibodies, and mediate host defence by eliminating intracellular pathogens (that is, by activating macrophages) and by killing virus infected cells. Which of these mechanisms are preferentially activated depends on the nature of the disease causing agent. A successful immune response, however, requires the coordination and participation of both non-specific and specific arms of the immune system as most of the immune competent cells and their products have overlapping and complementary functions.

\section{Probiotics and immune function}

The effect of probiotic intake on immune function has been the subject of several recent human studies. There is strong evidence to suggest that specific strains of lactic acid bacteria, when consumed in certain numbers, are able to modulate aspects of both natural and acquired immune responses.

\section{Probiotics and innate immune function}

The ability of specific strains of probiotics to enhance aspects of natural immunity in human subjects is well documented. Schiffrin and colleagues reported enhanced phagocytic capacity of peripheral blood leucocytes (polymorphonuclear and monocytes $)^{70}$ in healthy human adults administered fermented milk supplemented with specific strains of probiotics (Lactobacillus johnsonii Lal or Bifidobacterium lactis Bb12) for three weeks. The improvements in phagocytic activity were sustained for several weeks after cessation of probiotic consumption, ${ }^{70-72}$ and granulocytes showed higher increases in phagocytic cell function compared with monocytes. $^{70}{ }^{73}$ Significant increases in the expression of receptors involved in phagocytosis (CR1, CR3, Fc $\gamma$ RI and Fc $\alpha$ R) in neutrophils, ${ }^{69}$ phagocytic index, ${ }^{74}$ and oxidative burst ${ }^{73}{ }^{75}$ or microbicidal capacity ${ }^{71}$ in subjects receiving probiotics have also been reported. It has also been observed that different lactic acid bacteria strains differ in their capacity to influence complement receptor expression in phagocytic cells. For example, He et al found that Lactobacillus lactis was more efficient at upregulating complement receptors on blood leucocytes than $L$ rhamnosus ${ }^{76}$ Furthermore, the immunostimulatory effect of probiotic intake was dose dependent and a minimum dose of $10^{9} \mathrm{cfu} /$ day was found to be necessary to realise improvements in immune function. ${ }^{73}$

Ageing is associated with a decline in immunocompetence. It has been suggested that supplementation with probiotic could be used to correct age related decline in phagocytic cell function in the elderly. Subjects receiving milk containing $L$ rhamnosus (HN001) or B lactis (HN019) for three to six weeks were found to exhibit significantly more phagocytically active blood leucocytes (neutrophils and monocytes; fig l) than subjects receiving milk without probiotics. ${ }^{72} 77$ Notably, subjects with relatively poor preintervention phagocytic cell function consistently showed higher relative increases in phagocytic activity than subjects with adequate preintervention immune function. ${ }^{77}$ Furthermore, augmentation in phagocytic activity was found to be correlated with age, with subjects older than 70 years exhibiting significantly greater improvements in phagocytic activity than those under 70 years. $^{77}$

Significant improvements in NK cell activity, and increases in the percentage of $\mathrm{NK}$ cells in the peripheral blood of human volunteers fed yogurt, milk, or sausages containing probiotics have also been reported. ${ }^{74}{ }^{78-80}$ As with phagocytic cell function, augmentation of NK cell activity in the elderly following administration of lactic acid bacteria (fig 2) was also correlated with age. ${ }^{79}$

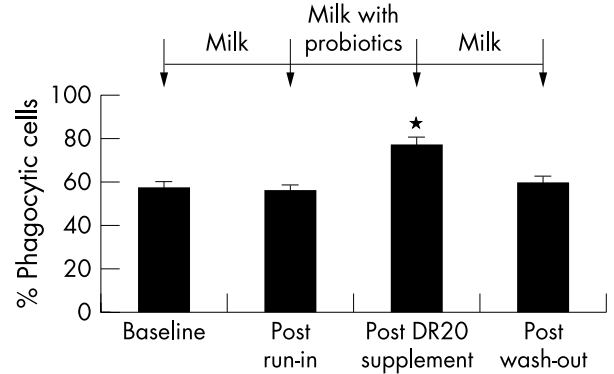

Figure 1 Polymorphonuclear cell phagocytic activity before and after consumption of $L$ rhamnosus $\mathrm{HNOO1}$ in healthy elderly subjects $(n=13$; five males, eight females; age 65-85 years). Subjects consumed low fat, low lactose milk (200 ml twice/day) as a base diet during the run-in stage for three weeks, followed by milk supplemented with $L$ rhamnosus $(5 \times 10 \mathrm{cfu}$ daily) for three weeks (intervention stage), before returning to non-supplemented low fat, low lactose milk for the final three weeks. Data are mean (SEM); *significantly higher response than preceding time points $(p<0.001$; repeat measure analysis of variance, Dunnett's post hoc test for significance). Adapted from Gill et al. ${ }^{78}$

Contrary to the studies discussed above, however, a lack of any immunomodulatory effect of probiotic intake on phagocytic cell function ${ }^{80}{ }^{81}$ has also been observed in several studies. Whether this was simply due to strain-dependent variation in the immunostimulatory capacity of the probiotic bacteria used or some other reason is not clear. Differences in the ability of lactic acid bacteria to influence immune function are well documented. ${ }^{82}$

\section{Humoral immune responses}

A large number of human studies have also shown that the intake of specific strains of lactic acid bacteria is able to potentiate humoral immune responses to natural infections and systemic or oral immunisation. In a randomised, placebo controlled study involving infants with acute rotavirus diarrhoea, Kaila et al observed that a reduced duration of diarrhoea after administration of Lactobacillus GG fermented milk was associated with augmentation of both rotavirus specific and non-specific antibody responses. ${ }^{83}$ At convalescence, $90 \%$ of the Lactobacillus GG group compared with $46 \%$ of the placebo group exhibited rotavirus specific IgA antibody secreting cell response. It is important to note, however, that a very low cut off level (0.05 antibody secreting cells $/ 10^{6}$ cells) was used as an indicator of seroconversion. Significantly higher $\operatorname{IgG}$, IgA, and $\operatorname{Ig} M$ immunoglobulin secreting cells in Lactobacillus $G G$ fed infants compared with those given a placebo were also observed. Comparison of

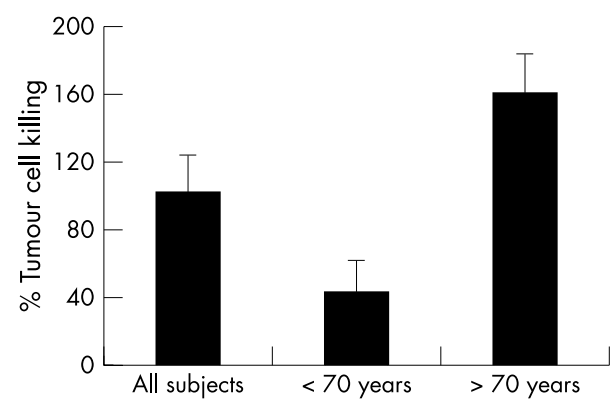

Figure 2 Relative increases in NK cell tumoricidal activity after consumption of milk supplemented with $L$ rhamnosus HNOO1. Data are mean (SEM) percentage increases in peripheral blood mononuclear cell tumoricidal activity between time point T1 (before probiotic supplementation - that is, after three week run-in period) and time point T2 (immediately after three weeks of $L$ rhamnosus supplementation). Adapted from Gill et al. ${ }^{78}$ 
different strains further revealed that Lactobacillus $G G$ was more efficient at stimulating IgA specific antibody secreting cells to rotavirus and serum IgA responses than $L$ casei subspecies rhamnosus or a combination of $S$ thermophilus and $L$ delbruckii subspecies bulgaricus. ${ }^{84}$ Furthermore, viable cells were found to be more efficacious at stimulating rotavirus specific immune response than heat inactivated cells. ${ }^{85}$

Effectiveness of probiotics in enhancing the immunogenicity of mucosal and systemic vaccines has also been reported. Link-Amster and colleagues reported fourfold increase $(\mathrm{p}=0.04)$ in serum IgA antibody response to Salmonella typhi immunisation, in volunteers consuming yoghurt containing $B$ bifidum and $L$ acidophilus Lal compared with a 2.5 -fold increases in the control group. ${ }^{86}$ Enhanced responsiveness (rotavirus specific IgM secreting cells and IgA seroconversion rate) to live oral rotavirus vaccine in infants fed Lactobacillus GG, compared with the control group, has also been reported.$^{87}$ Supplementation with specific strains of probiotics has also been shown to improve immune responses to immunisation with polioviruses. In a randomised, double blind, placebo controlled study, ${ }^{88}$ subjects fed yoghurt containing $L$ rhamnosus and $L$ paracasei showed significantly higher virus neutralising antibody responses (mainly IgA) to a live attenuated polioviruses vaccine, compared with subjects given placebo (chemically acidified milk); subjects receiving probiotic yoghurt also exhibited significantly higher polio specific serum IgG and IgA responses. In another study, administration of a formula supplemented with bifidobacteria significantly increased the levels of total faecal IgA and antipoliovirus faecal $\operatorname{IgA}^{89}$ in infants immunised against poliovirus several months before enrolment in the study. Together these observations suggest that specific strains of lactic acid bacteria are endowed with potent adjuvant properties that could be used for improving efficacy of oral vaccines and as immunostimulants to promote recovery from infectious illnesses. Development of immunisation strategies that avoid the use of needles, and non-toxic adjuvants is highly desirable as it will simplify immunisation programmes and reduce barriers to large scale immunisation.

It is to be noted that probiotic administration is also known to induce antibody responses to completely unrelated antigens and to themselves. ${ }^{86}{ }^{90}$ Therefore, it is possible that some of specific antibody activity detected in studies described above may in fact be due to non-specific cross reacting antibodies. The mechanisms by which probiotics potentiate humoral immune responses are not known but could be due to increased transport of antigenic materials across the gut and improved antigen-presenting cell function (upregulation of antigen presenting molecules and costimulatory molecules induced by proinflammatory cytokines $^{91}$ and/or increased number of B-cells. ${ }^{92}$

Although the studies reported above provide evidence of the immunoenhancing effects of certain probiotic strains, further well designed studies are needed to unequivocally demonstrate the efficacy of specific strains; only a small number of studies conducted to date have been randomised, double blind, and/or placebo controlled. Whether consumption over long periods will result in sustained improvements in immune capacity also remains to be determined. Also, little is known about the effective probiotic dose for different population groups, and the relevance of immunoenhancement to increased disease resistance.

The precise mechanisms by which probiotics influence the functioning of the immune system are not fully understood. It appears that recognition of probiotic associated molecular patterns (for example, peptidoglycans, lipotechoic acid, bacterial DNA) by pattern recognition receptors (such as toll-like receptors) present on the surface of immunocompetent cells (monocytes, macrophages, dendritic cells, etc), present in the Peyer's patches, lamina propria or other sites triggers the release of a range of cytokines that shape the developing immune response (unresponsiveness or active immune response). Several studies have reported increased production of a vast array of cytokines (for example, IL- l, IL2, IL-6, IL-10, IL-12, IL-18, TNF- $\alpha$, interferon- $\gamma$ ) following in vitro stimulation of blood leucocytes with lactic acid bacteria and/or oral consumption of probiotics. ${ }^{82}{ }^{93}$ These cytokines are known to exert a range of modulatory effects on immune cell function. ${ }^{21}$ For example, IL-12 and IL-18 induce interferon- $\gamma$ production by T-cells, B-cells and NK cells, and interferon- $\gamma$ enhances phagocyte mediated clearance of microbes, augments cytotoxic capacity of T-cells and NK cells, and stimulates helper T-cell function and augments immunogenicity of vaccines. TNF- $\alpha$ further increases the microbicidal activity of macrophages and exerts cytotoxic effect against tumours. Interferon- $\alpha$ mediates protection against viral and microbial infections and cancers, while IL-1 stimulates proliferation of T-cells and B-cells and IL-6 induces differentiation to antibody-secreting plasma cells. Transforming growth factor- $\beta$ and IL-10 possess potent anti-inflammatory properties and play an important part in immune system homoeostasis. IL-2 influences induction and regulation of Tcell mediated immune responses.

\section{ANTICANCER EFFECTS}

Several animal studies have shown that supplementation with specific strains of lactic acid bacteria (probiotics) could prevent the establishment, growth, and metastasis of transplantable and chemically induced tumours. ${ }^{94}$ Studies in human subjects have also revealed that probiotic therapy may reduce the risk of colon cancer by inhibiting transformation of procarcinogen to active carcinogens, binding/inactivating mutagenic compounds, producing antimutagenic compounds, suppressing the growth of pro-carcinogenic bacteria, reducing the absorption of mutagens from the intestine, and enhancing immune function. ${ }^{95}$ An inverse relationship between the consumption of fermented dairy products, containing lactobacilli or bifidobacteria, and the incidence of colon and breast cancer has also been reported in epidemiological and population based case-control studies. ${ }^{97} 98$

However, there is little "direct experimental evidence" regarding the anticancer effectiveness (tumour suppression) of probiotic therapy in humans. Aso and colleagues demonstrated the protective effect of $L$ casei strain Shirota on the recurrence of superficial bladder cancer in a randomised, controlled, multicentre study. ${ }^{99}$ Subjects were enrolled in the study within two weeks after removal of bladder tumours. After one year, tumour recurrence rate was significantly lower in subjects receiving $L$ casei $(57 \%)$ compared with the control group (83\%). Treatment with $L$ casei also delayed the onset of tumour recurrence. Similar observations were made in a second, much larger, placebo controlled study involving 125 patients by Aso and colleagues. ${ }^{100}$ Increases in the percentage of T-helper cells and NK cells in adult colorectal cancer patients ${ }^{101}$ suggest that stimulation of the immune system by $L$ casei Shirota may have an important role in the suppression of tumour development.

Carefully designed, long term human studies are needed to verify findings of animal studies and to establish a basis for probiotic therapy in cancer prevention.

\section{LOWERING OF BLOOD CHOLESTEROL}

Mann and Spoerry were the first to report that consumption of fermented milk was associated with reduced serum cholesterol levels in the Maasai people. ${ }^{102}$ This stimulated much interest in the cholesterol lowering effects of fermented milks and lactic acid bacteria. Several animal studies have 
shown that administration of fermented milks or specific strains of lactic acid bacteria is effective in lowering blood cholesterol levels. Studies in human subjects, however, have yielded conflicting results. For example, Lin et al reported a reduction in serum cholesterol from 5.7 to $5.3 \mathrm{mmol} / \mathrm{l}$ after seven weeks and to $5.4 \mathrm{mmol} / \mathrm{l}$ after 16 weeks in subjects given $L$ acidophilus and $L$ bulgaricus $(3 \times 10 \mathrm{cfu} /$ daily $)$ for 16 weeks; serum cholesterol levels remained unchanged in control subjects (without a placebo). ${ }^{103}$ However, in the second double blind, placebo controlled (crossover design) trial involving 460 volunteers (334 subjects completed the study), supplementation with these strains (two six week supplementation periods separated by a washout period of three weeks) was found to have no effect on serum cholesterol levels. Contradictory observations on the cholesterol lowering effects of yoghurt enriched with a specific strain of $L$ acidophilus have also been reported by others. While Shaafsma et al reported a reduction in serum cholesterol in subjects receiving yoghurt supplemented with $L$ acidophilus and fructo-oligosaccharides for weeks, ${ }^{104}$ de Roos et al found no effect of the consumption of yogurt containing $L$ acidophilus $\mathrm{Ll}$ on serum cholesterol in a placebo controlled study $(\mathrm{n}=78) .{ }^{105}$ Several factors, including differences in experimental design, differences in study subjects, intakes of fermented milk, and strains of bacteria used have been suggested to account for these conflicting observations.

A meta-analysis of controlled short term (4-8 weeks) studies $(\mathrm{n}=6)$ involving 425 subjects (male and female with different initial cholesterol levels) has shown that consumption of yoghurt containing Enterococcus faecium (Gaio) is effective in reducing both total and low density lipoprotein cholesterol by $4 \%$ and $5 \%$, respectively, compared with the control group. ${ }^{106}$ Whether the effects are sustained over a long time remains to be proven. Subjects given milk fermented with $E$ faecium for 24 weeks showed reduction in serum cholesterol levels at four and 12 weeks but not at 24 (end of the study) and 30 weeks (after the follow up). ${ }^{107}$ Consumption of Pro Viva (Probi AB, Sweden) food product containing L plantarum 299v (randomised, placebo controlled study) has also been reported to lower total and low density lipoprotein cholesterol in subjects with moderately raised cholesterol levels. ${ }^{108}$

Furthermore, it has been reported that long term consumption of fermented products enriched with specific strains of lactic acid bacteria may be effective in increasing high density lipoprotein cholesterol. In a single blind parallel study, subjects consuming milk fermented with $L$ casei TMC 0409 and $S$ thermophilus TMC 1543 (200 ml/day) showed significant increases, compared with the pre-intervention levels, in high density lipoprotein levels after four and eight weeks supplementation. ${ }^{109}$ The levels of triglycerides were also reduced significantly in subjects receiving the fermented milk. No significant changes were noted in the control group. Consumption of $300 \mathrm{~g}$ yoghurt supplemented with $L$ acidophilus 145 and Bifidobacterium longum 913 for seven weeks was also found to increase high density lipoprotein concentration by $0.3 \mathrm{mmol} / \mathrm{l}(\mathrm{p}=0.002)$ and decrease ratio of low to high density lipoprotein from 3.24 to $2.48(p=0.001){ }^{110}$ However, the concentrations of total and low density lipoprotein cholesterol in serum remained unaffected by the consumption of probiotic yoghurt; relatively high fat content of the yoghurt $(3.5 \%)$ was suggested to be the main reason for the lack of effect.

The precise mechanisms by which probiotics affect cholesterol levels are not fully understood. However, a range of mechanisms include assimilation of cholesterol by bacterial cells, deconjugation of bile acids by bacterial acid hydrolases (reduces cholesterol reabsorption, increases cholesterol excretion of deconjugated bile salts, and increases cholesterol uptake by low density lipoprotein receptor pathway in the liver as a compensatory response), cholesterol binding to bacterial cell walls, and inhibition of hepatic cholesterol synthesis and/or redistribution of cholesterol from plasma to the liver (through the action of short chain fatty acids, the end products of carbohydrate fermentation in the gut). ${ }^{111}$

\section{LACTOSE MALABSORPTION}

Prevalence of lactose malabsorption in adult populations varies from $5 \%$ to $15 \%$ in northern European and American countries and $50 \%$ to $100 \%$ in African, Asian, and South American countries. ${ }^{112}$ It is well recognised that bacteria used as starter culture in yogurt ( $S$ thermophilus and Lactobacillus delbrueckii subspecies bulgaricus) improve lactose digestion. ${ }^{113}$ The benefit is due to the presence of microbial $\beta$-galactosidase (lactase) in the bacteria. A large number of human studies in which consumption of fresh yogurt (with live yogurt cultures) was compared with consumption of a pasteurised product (with heat killed bacteria), demonstrated better lactose digestion and absorption in subjects that consumed yogurt with live cultures as well as reduction of gastrointestinal symptoms. ${ }^{114-121}$

\section{IRRITABLE BOWEL SYNDROME}

Symptoms of abdominal pain, bloating, flatulence, and diarrhoea are commonly seen in patients with irritable bowel syndrome, and abdominal pain and bloating are difficult to treat and have a significant impact on patients' lives. Bacteria in the gut flora can produce intestinal gas but they also consume gas. Theoretically, probiotics might improve the balance and reduce gas accumulation within the bowel. In a double blind clinical trial, administration of a $L$ plantarum strain decreased pain and flatulence in patients with irritable bowel syndrome. ${ }^{122}$ Likewise, a recent placebo controlled trial concluded that the VSL\#3 probiotic mixture is useful for the relief of abdominal bloating in patients with diarrhoea predominant irritable bowel syndrome, and the effect is unrelated to an alteration in gastrointestinal or colonic transit. ${ }^{123}$ Probiotics need to be evaluated further but they appear to be useful for the control of symptoms due to the altered handling or perception of intestinal gas in this group of patients.

\section{PROBIOTICS IN EVIDENCE BASED GASTROENTEROLOGY}

Box 2 summarises the grade of recommendations for the use of probiotics in gastroenterology according to the criteria of evidence based medicine. Grade recommendations should be implemented in patient care, and are supported by level 1 evidence. Level lA evidence represents evidence from high quality randomised controlled trials with statistically significant results and few limitations in their design, or by conclusions from systematic reviews of the trials. Level $1 \mathrm{~B}$ evidence comes from single high quality clinical trials that have clearly shown positive or negative results with narrow intervals of confidence, so that it is unlikely that the trend would change in future studies. Grade B recommendations favour a therapeutic option that is supported by level 2 evidence. This evidence refers to randomised controlled trials that have some limitations in their study methodology or results showing wide confidence intervals. Grade B recommendations could change in the future, especially if level 1 evidence from new studies becomes available.

\section{FUTURE PERSPECTIVES}

The future will see the development of new, well characterised, scientifically proven probiotic strains with specific health benefits. In addition to the clinically proven benefits 


\section{Box 2: Probiotics in evidence based medicine}

Grade A recommendation (level 1A evidence)

- Treatment of acute infectious diarrhoea in children.

- Prevention of antibiotic associated diarrhoea.

- Prevention of nosocomial and community acquired diarrhoea in children.

- Treatment of lactose malabsorption.

Grade A recommendation (level 1B evidence)

- Prevention of pouchitis and maintenance of remission.

- Prevention of postoperative infections.

- Prevention and management of paediatric atopic diseases.

Grade B recommendation (level 2B evidence)

- Prevention of travellers' diarrhoea.

- Prevention of sepsis associated with severe acute pancreatitis.

- Maintenance of remission of ulcerative colitis.

- Lowering of blood cholesterol.

(grade A recommendations) described above, the use of probiotics for the prevention and management of over expressed immune function such as atopy and inflammatory bowel diseases, and for enhancing immune function and improving efficacy of vaccines in population groups with less than optimum immune functions (for example, infants, elderly, immunocompromised) hold great promise. New DNA based technologies offer unique opportunities to elucidate mechanisms by which probiotics mediate their disparate effects (including identification of microbial signals that fortify mucosal barrier and regulate mucosal immune function), and develop genetically modified probiotics with specific immunomodulatory properties and as carriers of therapeutic molecules.

\section{MULTIPLE CHOICE QUESTIONS (ANSWERS AT END OF REFERENCES)}

1. The highest density and diversity of intestinal microflora is found in:
(A) Oral cavity
(B) Stomach
(C) Duodenum
(D) Ileum
(E) Colon

2. Administration of probiotics is clinically proven (grade A level recommendation; level $1 \mathrm{~A}$ evidence) to be effective in the prevention of:
(A) Breast cancer
(B) Colon cancer
(C) Hypercholestrolaemia
(D) Antibiotic associated diarrhoea
(E) Travellers' diarrhoea

3. Best recommendation to subjects with a diagnosis of lactose malabsorption is:

(A) To avoid milk and dairy products

(B) To avoid milk and ice creams, but consumption of yogurt and cheese is occasionally allowed

\section{Box 3: Key references}

- Gruaner F, Malagelada J-R. Gut flora in health and disease. Lancet 2002;360:512-19.

- Teitelbaum JE, Walker WA. Nutritional impact of preand probiotics as protective gastrointestinal organisms. Annu Rev Nutr 2002;22:107-38.

- Marteau P, Seksik P, Jian R. Probiotics and intestinal health effects: a clinical perspective. $\mathrm{Br} J$ Nutr 2002;88(suppl 1):S51-7.

- Szajewska H, Mrukowicz JZ. Probiotics in the treatment and prevention of acute infectious diarrhea in infants and children: a systematic review of published randomized, double-blind, placebo-controlled trials. J Pediatr Gastroenterol Nutr 2001;33:S17-S25.

- Gill HS. Probiotics to enhance anti-infective defences in the gastrointestinal tract. Best Pract Res Clin Gastroenterol 2003;17:755-73.

- Tamboli CP, Caucheteux C, Cortot A, et al. Probiotics in inflammatory bowel disease: a critical review. Best Pract Res Clin Gastroenterol 2003;17:805-20.

(C) To consume yogurt and cheese regularly, and to take a yogurt before consuming milk or ice cream occasionally

(D) To take antidiarrhoeal drugs (for example, loperamide) before consuming milk or dairy products

(E) To consume soy based milk

4. People travelling to countries with risk of acute infectious diarrhoea should be advised to:

(A) Avoid tap water, peeled fruits, and salads

(B) Take norfloxacin $400 \mathrm{mg}$ per day as a prophylaxis

(C) Take Lactobacillus strain GG in dairy products or pills at a dose of $10^{9} \mathrm{cfu} /$ day.

(D) All three recommendations are fine but unproven

(E) None of these recommendations is useful

5. Children attending day care centres or admitted into hospital wards may benefit from regular intake of probiotics in order to:

(A) Improve their nutritional support

(B) Prevent acute diarrhoea by rotavirus

(C) Prevent upper respiratory tract infection

(D) Prevent atopic eczema or other allergic diseases

(E) Enhance their immune function

\section{Authors' affiliations}

H S Gill, Primary Industries Research Victoria, Department of Primary Industries, Werribee, Victoria, Australia and Institute of Food, Nutrition and Human Health, Massey University, Palmerston North, New Zealand F Guarner, Digestive System Research Unit, University Hospital Vall d'Hebron, Barcelona, Spain

\section{REFERENCES}

1 Holzapfel WH, Hebrer P, Snel J, et al. Overview of gut flora and probiotics. Int J Food Microbiol 1998;41:85-101.

2 Bullen CL, Tearle PV, Stewart MG. The effect of "humanised" milks and supplemented breastfeeding on the faecal flora of infants. Int I Med Microbiol 1977; 10:403-13.

3 Hooper LV, Gordon Jl. Commensal host-bacterial relationships in the gut. Science 2001;292:1115-18. 
4 Gruaner F, Malagelada J-R. Gut flora in health and disease. Lancet 2002;360:512-19.

5 Hart AL, Stagg AJ, Frame M, et al. Review article: the role of the gut flora in health and disease, and its modification as therapy. Aliment Pharmacol Ther 2002;16:1383-93.

6 Teitelbaum JE, Walker WA. Nutritional impact of pre- and probiotics as protective gastrointestinal organisms. Annu Rev Nutr 2002;22:107-38.

7 Marteau P, Seksik P, Jian R. Probiotics and intestinal health effects: a clinical perspective. Br J Nutr 2002;88(suppl 1):S51-7.

8 D'Souza AL, Rajkumar C, Cooke J, et al. Probiotics in prevention of antibiotic associated diarrhoea: meta-analysis. BMJ 2002;324:1361-6.

9 Cremonini F, Di Caro S, Nista EC, et al. Meta-analysis: the effect of probiotic administration on antibiotic-associated diarrhoea. Aliment Pharmacol Ther 2002;16:1461-7.

10 Saavedra JM, Bauman NA, Oung I, et al. Feeding of Bifidibacterium bifidum and Streptococcus thermophilus to infants in hospital for prevention of diarrhoea and shedding of rotavirus. Lancet 1994;344:1046-9.

11 Szajewska H, Kotowska M, Mrukowicz JZ, et al. Efficacy of Lactobacillus GG in prevention of nosocomial diarrhea in infants. J Pediatr 2001;138:361-5.

12 Mastretta E, Longo P, Laccisaglia A, et al. Effect of Lactobacillus GG and breast-feeding in the prevention of rotavirus nosocomial infection. J Pediatr Gastroenterol Nutr 2002;35:527-31

13 Oberhelman RA, Gilman RH, Sheen P, et al. A placebo-controlled trial of Lactobacillus GG to prevent diarrhea in undernourished Peruvian children. J Pediatr 1999;134:15-20.

14 Pedone CA, Arnaud CC, Postaire ER, et al. Multicentric study of the effect of milk fermented by Lactobacillus casei on the incidence of diarrhoea. Int $J$ Clin Pract 2000;54:568-71.

15 Marteau P, Seksik P, Jian R. Probiotics and intestinal health effects: a clinical perspective. Br J Nutr 2002;88(suppl 1):S51-7

16 Szajewska H, Mrukowicz JZ. Probiotics in the treatment and prevention of acute infectious diarrhea in infants and children: a systematic review of published randomized, double-blind, placebo-controlled trials. J Pediatr Gastroenterol Nutr 2001;33:S17-S25.

17 Van Niel CW, Feudtner C, Garrison MM, et al. Lactobacillus therapy for acute infectious diarrhea in children: a meta-analysis. Pediatrics 2002; 109:678-84.

18 Huang JS, Bousvaros A, Lee JW, et al. Efficacy of probiotic use in acute diarrhea in children: a meta-analysis. Dig Dis Sci 2002;47:2625-34.

19 Wendakoon CN, Thomson AB, Ozimek L. Lack of therapeutic effect of a specially designed yogurt for the eradication of Helicobacter pylori infection. Digestion 2002;65:16-20.

20 Sheu BS, Wu JJ, Lo CY, et al. Impact of supplement with Lactobacillus- and Bifidobacterium-containing yogurt on triple therapy for Helicobacter pylori eradication. Aliment Pharmacol Ther 2002;16:1669-75.

21 Gill HS. Probiotics to enhance anti-infective defences in the gastrointestinal tract. Best Pract Res Clin Gastroenterol 2003;17:755-73.

22 Lichtman SM. Bacterial translocation in humans. J Pediatr Gastroenterol Nutr 2001;33:1-10.

23 Olah A, Belagyi T, Issekutz A, et al. Randomized clinical trial of specific lactobacillus and fibre supplement to early enteral nutrition in patients with acute pancreatitis. Br J Surg 2002;89:1103-7.

24 Rayes N, Seehofer D, Hansen S, et al. Early enteral supply of lactobacillus and fiber versus selective bowel decontamination: a controlled trial in liver transplant recipients. Transplantation 2002;74:123-7.

25 Rayes N, Seehofer D, Theruvath T, et al. Perioperative enteral supply of a novel synbiotic composition postoperative bacterial infections in human live transplantation-a randomized, double-blind clinical trial. Hepatology (in press).

26 Macpherson A, Khoo UY, Forgacs I, et al. Mucosal antibodies in inflammatory bowel disease are directed against intestinal bacteria. Gut 1996;38:365-75.

27 Pirzer U, Schönhaar A, Fleischer B, et al. Reactivity of infiltrating T lymphocytes with microbial antigens in Crohn's disease. Lancet 1991;338:1238-9.

28 D'Haens GR, Geboes K, Peeters M, et al. Early lesions of recurrent Crohn's disease caused by infusion of intestinal contents in excluded ileum. Gastroenterology 1998;114:262-7.

29 Casellas F, Borruel N, Papo M, et al. Antiinflammatory effects of enterically coated amoxicillin-clavulanic acid in active ulcerative colitis. Inflamm Bowel Dis 1998;4:1-5.

30 Borruel N, Carol M, Casellas F, et al. Increased mucosal TNF- $\alpha$ production in Crohn's disease can be downregulated ex vivo by probiotic bacteria. Gut 2002;51:659-64.

31 Borruel N, Casellas F, Antolín M, et al. Effects of nonpathogenic bacteria on cytokine secretion by human intestinal mucosa. Am J Gastroenterol 2003;98:865-70.

32 Madsen K, Cornish A, Soper P, et al. Probiotic bacteria enhance murine and human intestinal epithelial barrier function. Gastroenterology 2001;121:580-91

33 Schultz M, Veltkamp C, Dieleman LA, et al. Lactobacillus plantarum 299V in the treatment and prevention of spontaneous colitis in interleukin-10-deficient mice. Inflamm Bowel Dis 2002;8:71-80.

34 Kennedy RJ, Hoper M, Deodhar K, et al. Probiotic therapy fails to improve gut permeability in a hapten model of colitis. Scand J Gastroenterol 2000;35:1266-71

35 Steidler L, Hans W, Schotte L, et al. Treatment of murine colitis by Lactococcus lactis secreting interleukin-10. Science 2000;289:1352-5.

36 Videla S, Vilaseca J, Antolín $M$, et al. Dietary inulin improves distal colitis induced by dextran sodium sulfate in the rat. Am J Gastroenterol $2001 ; 96: 1486-93$
37 Kruis W Schutz E, Fric $P$, et al. Double-blind comparison of an oral Escherichia coli preparation and mesalazine in maintaining remission of ulcerative colitis. Aliment Pharmacol Ther 1997;1 1:853-8.

38 Rembacken BJ, Snelling AM, Hawkey PM, et al. Non-pathogenic Escherichia coli versus mesalazine for the treatment of ulcerative colitis: a randomised trial. Lancet 1999:354:635-9.

39 Malchow HA. Crohn's disease and Escherichia coli. J Clin Gastroenterol 1997;25:653-8.

40 Gionchetti $\mathbf{P}$, Rizzello F, Venturi A, et al. Oral bacteriotherapy as maintenance treatment in patients with chronic pouchitis: a double-blind, placebo-controlled trial. Gastroenterology 2000;1 19:305-9.

41 Gionchetti P, Rizzello F, Helwig U, et al. Prophylaxis of pouchitis onset with probiotic therapy: a double-blind, placebo-controlled trial. Gastroenterology 2003;124:1202-9.

42 Campieri M, Rizzello F, Venturi A, et al. Combination of antibiotic and probiotic treatment is efficacious in prophylaxis of post-operative recurrence of Crohn's disease: a randomized controlled study vs mesalamine. Gastroenterology 2000;118:A4179.

43 Prantera C, Scribano ML, Falasco G, et al. Ineffectiveness of probiotics in preventing recurrence after curative resection for Crohn's disease: a randomised controlled trial with Lactobacillus GG. Gut 2002;51:405-9.

44 Kuisma J, Mentula S, Jarvinen H, et al. Effect of Lactobacillus rhamnosus GG on ileal pouch inflammation and microbial flora. Aliment Pharmacol Ther 2003;17:509-15

45 Guslandi M, Mezzi G, Sorghi M, et al. Saccharomyces boulardii in maintenance treatment of Crohn's disease. Dig Dis Sci 2000;45:1462-4.

46 Welters CF, Heineman E, Thunnissen FB, et al. Effect of dietary inulin supplementation on inflammation of pouch mucosa in patients with an ileal pouch-anal anastomosis. Dis Colon Rectum 2002;45:621-7.

47 Tamboli CP, Caucheteux C, Cortot A, et al. Probiotics in inflammatory bowel disease: a critical review. Best Pract Res Clin Gastroenterol 2003; 17:805-20.

48 Matricardi PM, Rosmini F, Rapicetta M, et al. Atopy, hygiene, and anthroposophic lifestyle. Lancet 1999;354:430.

49 Bjorksten B, Naaber P, Sepp E, et al. The intestinal microflora in allergic Estonian and Swedish 2-year-old children. Clin Exp Allergy 1999;29:342-6.

50 Kalliomaki M, Kirjavainen $\mathrm{P}$, Eerola $\mathrm{E}$, et al. Distinct patterns of neonatal gut microflora in infants in whom atopy was and was not developing. J Allergy Clin Immunol 2001; 107:129-34.

51 Matricardi PM, Bjorksten B, Bousquet J, et al. Microbial products in allergy prevention and therapy. Allergy 58:461-71.

52 Lodinova-Zadnikova R, Cukrowska B, Tlaskalova-Hagenova H. Oral adminstration of probiotic Escherichia coli after birth reduces frequency of allergies and repeated infections later in life (after 10 and 20 years). Int Arch Allergy Immunol 2003;131:209-11.

53 Kalliomrki M, Salminen S, Arvllommi $\mathrm{H}$, et al. Probiotics in primary prevention of atopic disease: a randomised placebo-controlled trial. Lancet 2001;357:1076-9

54 Kalliomaki M, Salminen S, Poussa T, et al. Probiotic and prevention of atopic disease: 4-year follow-up of a randomised placebo-controlled trial. Lancet 2003:361:1869-71.

55 Loskutova IE. Effectiveness of using Maliutka and Malysh adapted propionicacidophilus mixtures in the combined treatment of congenital hypotrophy. Vopr-Pitan 1985 May/June:17-20.

56 Ciprandi G, Scordamaglia A, Ruffoni S, et al. Effects of an adjunctive treatment with Bacillus subtilis for food allergy. Chemioterapia 5:408-10.

57 Majamaa $\mathrm{H}$, Isolauri E. Probiotics: a novel approach in the management of food allergy. J Allergy Clin Immunol 1997;99:179-85.

58 Isolauri E, Arvola T, Sutas $Y$, et al. Probiotics in the management of atopic eczema. Clin Exp Allergy 2000;30:1604-10.

59 Rosenfeldt V, Benfeldt E, Nielsen SD, et al. Effect of probiotics Lactobacillus strains in children with atopic dermatitis. J Allergy Clin Immunol 2003; 111:390-5.

60 Kirjavainen PV, Salminen SJ, Isolauri E. Probiotic bacteria in the management of atopic disease: underscoring the importance of viability. J Pediatr Gastroenterol Nutr 2003;36:223-7.

61 Trapp CL, Chang CC, Halpern GM, et al. The influence of chronic yogurt consumption on populations of young and elderly adults. Int $J$ Immunother 1993:9:53-64.

62 Helin S, Haahtela S, Haahtela T. No effect of oral treatment withintestinal bacterial strain, Lactobacillus rhamnosus (ATCC 53103), on birch-pollen allergy: a placebo-controlled double-blind study. Allergy 2002;57:243-6.

63 Wheeler JG, Shema SJ, Bogle ML, et al. Immune and clinical impact of Lactobacillus acidophilus on asthma. Ann Allergy Asthma Immunol 1997;79:229-33.

64 von der Weid T, Bulliard C, Schiffrin E. Induction by a lactic acid bacterium of a population of CD4 T cells with low proliferative capacity that produce transforming growth factor and IL-10. Clin Diagnost Lab Immunol 2001;8:695-701.

65 Rokka T, Syvaoja EL, Tuomine J, et al. Release of bioactive peptides by enzymatic proteolysis of Lactobacillus GG fermented UHT milk. Milchwissenschaft 1997:52:675-8.

66 Kirjavainen PV. Probiotics and the management of food allergy. In: MattilaSandholm T, Saarela M, eds. Functional dairy products. Cambridge, UK: Woodhill Publishing, 2003:108-31

67 Rautava S, Kalliomaki M, Isolauri E. Probiotics during pregnancy and breast-feeding might confer immunomodulatory protection against atopic disease in the infant. J Allergy Clin Immunol 2002;109:119-21.

68 Pessi T, Sutas Y, Hurme M, et al. Interleukin-10 generation in atopic children following oral Lactobacillus rhamnosus GG. Clin Exp Allergy 2000;30:1804-8. 
69 Pelto L, Isolauri E, Lilius EM, et al. Probiotic bacteria down-regulate the milk induced inflammatory response in milk-hypersensitive subjects but have an immunostimulatory effect in healthy subjects. Clin Exp Allergy Immunol 1998;28:1474-9.

70 Schiffrin EJ, Rochar F, Link-Amster $\mathrm{H}$, et al. Immunomodulation of human blood cells following the ingestion of lactic acid bacteria. J Dairy Sci 1995;78:491-7.

71 Arunachalam K, Gill HS, Chandra RK. Enhancement of natural immune function by dietary consumption of Bifidobacterium lactis (HNO19). Eur J Clin Nutr 2000;54:1-5.

72 Sheih YH, Chiang BL, Wang LH, et al. Demonstration of systemic immunityenhancing effects in healthy subjects following dietary consumption of the lactic acid bacterium Lactobacillus rhamnosus HNOO1. J Am Coll Nutr 2001;20:149-56.

73 Donnet-Hughes A, Rochat F, Serrant P, et al. Modulation of nonspecific mechanisms of defense by lactic acid bacteria: effective dose. J Dairy Sci 1999;82:863-9.

74 Jahreis G, Vogelsang H, Kiessling G, et al. Influence of probiotic sausage (lactobacillus paracasei) on blood lipids and immunological parameters of healthy volunteers. Food Res Int 2002;35:133-8.

75 Mikes Z, Ferenicik M, Jahnova E, et al. Hypocholesterolemic and immunostimulatory effects of orally applied Enterococcus faecium M-74 in man. Folia Microbiologica 1995;40:639-46.

76 He F, Tuomola E, Arvilommi H, et al. Modulation of humoral immune response through probiotic intake. FEMS Immunol Med Microbiol 2000;29:47-52.

77 Gill HS, Rutherfurd KJ, Gopal P, et al. Enhancement of immunity in the elderly by dietary supplementation with the probiotic Bifidobacterium lactis HNO19. Am J Clin Nutr 2001;74:833-9.

78 Gill HS, Cross ML, Rutherfurd KJ, et al. Dietary probiotic supplementation to enhance cellular immunity in the elderly. Br J Biomed Sci 2001;58:94-6.

79 Gill HS, Rutherfurd KJ, Cross ML. Dietary probiotic supplementation enhances natural killer cell activity in the elderly: an investigation of agerelated immunological changes. J Clin Immunol 2001;21:264-71.

80 Spanhaak S, Havenaar R, Schaafsma G. The effect of consumption of milk fermented by Lactobacillus casei strain Shirota on the intestinal microflora and immune parameters in humans. Eur J Clin Nutr 1998;52:899-907.

81 Yoon H, Dubarry M, Bouley C, et al. New insights in the validation of specific biomarkers for the evaluation of the immunoregulatory properties of milk fermented with yogurt culture Lactobacillus casei (ACTIMEL): a prospective trial. Int J Immunother 1999;15:79-89.

82 Gill HS. Stimulation of the immune system by lactic cultures. Int Dairy J 1998:8:535-44.

83 Kaila $M$, Isolauri E, Soppi E, et al. Enhancement of the circulating antibody secreting cell response in human diarrhoea by a human Lactobacillus strain. Pediatr Res 1992;32:141-4.

84 Majamaa $H$, Isolauri $E$, Saxelin $M$, et al. Lactic acid bacteria in the treatment of acute rotavirus gastroenteritis. J Pediatr Gastroenterol Nutr 1995;20:333-8.

85 Kaila $M$, Isolauri $E$, Saxelin $M$, et al. Viable versus inactivated Lactobacillus strain GG in acute rotavirus diarrhoea. Arch Dis Child 1995;72:51-3.

86 Link-Amster H, Rochat F, Saudan KY, et al. Modulation of a specific humoral immune response and changes in intestinal flora mediated through fermented milk intake. FEMS Immunol Med Microbiol 1994; 10:55-64.

87 Isolauri E, Joensus J, Suomalainen $\mathrm{H}$, et al. Improved immunogenicity of oral D XRRV reabsorbant rotavirus vaccine by Lactobacillus casei GG. Vaccine 1995: 13:310-12.

88 de Vrese $M$, Fenselau S, Feindt $F$, et al. Einfluss von Probiotika auf die immunantwort auf eine polioschluckimpfung (Effects of probiotics on immune response to polio vaccination). Proc German Nutr Soc 2001;3:7.

89 Fukushima $\mathrm{Y}, \mathrm{Kawata} \mathrm{Y}$, Hara $\mathrm{H}$, et al. Effect of a probiotic formula on intestinal immunoglobulin A production in healthy children. Int $J$ Food Microbiol 1998;42:39-44.

90 Yasui H, Mike A, Ohwaki M. Immunogenicity of Bifidobacterium breve and change in antibody production in Peyer's patches after oral administration. J Dairy Sci 1989;72:30-5.

91 Heyman $M$. How dietary antigens access the mucosal immune system. Proc Nutr Soc $2001 ; 60: 419-26$

92 De Simone C, Rosati E, Moretti S, et al. Probiotics and stimulation of the immune response. Eur J Clin Nutr 1991:45(suppl):32-4.

93 Meydani SN, Ha WK. Immunologic effects of yogurt. Am J Clin Nutr 2000;71:861-72.

94 Rafter J. Lactic acid bacteria and cancer. Br J Nutr 2002;88(suppl 3):89-94.

95 Van't Veer P, Dekker JM, Lamers JWJ, et al. Consumption of fermented milk products and breast cancer: a case-control study in the Netherlands. Cancer Res 1989;49:4020-3.

96 Gill HS, Cross ML. Probiotics and immune function. In: Calder PC, Field CJ Gill HS, eds. Nutrition and immunity. Wallingford, UK: CABI International, 2001:251-72.

97 Van't Veer P, van Leer EM, Rietdijk A, et al. Combination of dietary factors in relation to breast-cancer occurrence. Int J Cancer 1991;47:649-53

98 Kampman E, Goldbohm RA, van den Brandt PA, et al. Fermented dairy products, calcium, and colorectal cancer in the Netherlands cohort study. Cancer Res 1994;54:363-5.

99 Aso Y, Akaza H, Kotake T. Prophylactic effect of a Lactobacillus casei preparation on the recurrence of superficial bladder cancer. Urol Int 1992:49:125-9.

100 Aso Y, Akaza H, Kotake T, et al. Preventive effect of a Lactobacillus casei preparation on the recurrence of superficial bladder cancer in a double-blind trial. Eur Urol 1995;27:104-9.
101 Sawamura A, Yamaguchi Y, Toge T, et al. Enhancement of immuno-activities by oral administration of Lactobacillus casei in colorectal cancer patients. Biotherapy 1994;8:1567-72.

102 Mann GV, Spoerry A. Studies of a surfactant and cholesteremia in the Maasai. Am J Clin Nutr 1974;27:464-9.

103 Lin SY, Ayres JW, Winkler W, et al. Lactobacillus effects on cholesterol: in vitro and in vivo results. J Dairy Res 1989;72:2885-99.

104 Schaafsma G, Meuling WJA, Van Dokkum W, et al. Effects of a milk product, fermented by Lactobacillus acidophilus and with fructooligosaccharides added, on blood lipids in male volunteers. Eur J Clin Nutr 1998;52:436-40.

105 De Roos NM, Schouten G, Katan MB. Yoghurt enriched with Lactobacillus acidophilus does not lower blood lipids in healthy men and women with normal to borderline high serum cholesterol levels. Eur J Clin Nutr 1999.53:277-80.

106 Agerholm-Larsen L, Bell ML, Grunwald GK, et al. The effect of probiotic milk product on plasma cholesterol: a meta-analysis of short-term intervention studies. Eur J Clin Nutr 2000:54:856-60.

107 Richelsen B, Kristensen K, Pedersen SB. Long-term (6 months) effect of a new fermented milk product on the level of plasma lipoproteins-a placebocontrolled and double blind study. Eur J Clin Nutr 1996;50:81 1-15.

108 Bukowska H, Pieczul-Mroz J, Chelstowsky K, et al. Effect of Lactobacillus plantarum (proviva) on LDL-cholesterol and fibrinogen levels in subjects with moderately elevated choledterol. Atherosclerosis 1997;134:325-32.

109 Kawase M, Hoshimoto H, Hosoda M, et al. Effect of administration of fermented milk containing whey protein concentrate to rats and healthy men on serum lipids and blood pressure. J Dairy Sci 1999;83:255-63.

110 Kiebling G, Schneider J, Jahreis G. Long-term consumption of fermented dairy products over 6 months increases HDL cholesterol. Eur J Clin Nutr 2002;56:843-9

111 Lovegrove J, Jackson K. Coronary heart disease. In: Mattila Sandholm T, Saarela M, eds. Functional dairy products. Cambridge, UK: Woodhil Publishing, 2003:54-87.

112 de Vrese M, Stegelmann A, Richter B, et al. Probiotics-compensation for lactase insufficiency. Am J Clin Nutr 2001;73(suppl):421S-29S.

113 Kolars JC, Levitt MD, Aouji M, et al. Yogurt-an autodigesting source of lactose. N Engl J Med 1984;310:1-3.

114 Savaiano DA, Abou ElAnouar A, Smith DE, et al. Lactose malabsorption from yogurt, pasteurized yogurt, sweet acidophilus milk, and cultured milk in lactase-deficient individuals. Am J Clin Nutr 1984;40:1219-23.

115 Dewit O, Pochart P, Desjeux J-F. Breath hydrogen concentration and plasma glucose, insulin and free fatty acid levels after lactose, milk, fresh or heated yogurt ingestion by healthy young adults with or without lactose malabsorption. Nutrition 1988;4:131-5.

116 Lerebours E, N'Ditoyap Ndam C, Lavoine A, et al. Yogurt and fermentedthen-pasteurized milk: effects of short-term and long-term ingestion on lactose absorption and mucosal lactase activity in lactase-deficient subjects. Am J Clin Nutr 1989;49:823-7.

117 Marteau P, Flourie B, Pochart P, et al. Effect of the microbial lactase (EC 3.2.1.23) activity in yoghurt on the intestinal absorption of lactose: an in vivo study on lactase deficient humans. Br J Nutr 1990;64:71-9.

118 Varela-Moreiras G, Antoine JM, Ruiz-Roso B, et al. Effects of yogurt and fermented-then-pasteurized milk on lactose absorption in an institutionalized elderly group. J Am Coll Nutr 1992;1 1:168-71.

119 Rizkalla SW, Luo J, Kabir M, et al. Chronic consumption of fresh but not heated yoghurt improves breath-hydrogen status and short-chain fatty acid profiles: a controlled study in healthy men with or without lactose maldigestion. Am J Clin Nutr 2000;72:1474-9.

120 Labayen I, Forga L, González A, et al. Relationship between lactose digestion, gastrointestinal transit time and symptoms in lactose malabsorbers after dairy consumption. Aliment Pharmacol Ther 2001;15:543-9.

121 Pelletier X, Laure-Boussuge S, Donazzolo Y. Hydrogen excretion upon ingestion of dairy products in lactose-intolerant male subjects: importance of the live flora. Eur J Clin Nutr 2001;55:509-12.

122 Nobaek S, Johansson ML, Molin G, et al. Alteration of intestinal microflora is associated with reduction in abdominal bloating and pain in patients with irritable bowel syndrome. Am J Gastroenterol 2000;95:1231-8.

$123 \mathrm{Kim}$ HJ, Camilleri M, McKinzie S, et al. A randomized controlled trial of a probiotic, VSL\#3, on gut transit and symptoms in diarrhoea-predominant irritable bowel syndrome. Aliment Pharmacol Ther 2003;17:895-904.

\section{ANSWERS}

1. Correct answer is (E). Colon contains a complex microbial ecosystem with highest density $\left(10^{11-12} \mathrm{cfu} / \mathrm{g}\right.$ of luminal contents) of living bacteria. About $60 \%$ of the faecal mass consist of bacteria. 2. Correct answer is (D). Controlled studies have shown that coadminstration of probiotics to patients on antibiotic therapy can reduce the incidence of antibiotic associated diarrhoea in children and adults. 3. Correct answer is (C). People with lactose malabsorption tend to avoid milk and dairy products and their calcium intake is compromised. Soy based milks are poor in calcium. They tolerate lactose well when ingested together with fresh yogurt as a source of lactase. 4. Correct answer is (D). Studies on these three approaches (A, B, C) suggest a benefit, but level of evidence is still insufficient. 5. Correct answer is 
(B). Controlled studies have shown that probiotics can prevent nosocomial diarrhoea by rotavirus. Children in hospital settings and day care centres are at risk of presenting acute diarrhoea by rotavirus or respiratory tract infections, but the value of probiotics for prevention of respiratory infectious is not proven. Observational studies suggest that children attending nurseries or day care centres have lower risk of atopic disease.

\section{IMAGES IN MEDICINE}

\section{Cholecystocolic fistula demonstrated by endoscopic retrograde cholangiopancreatography}

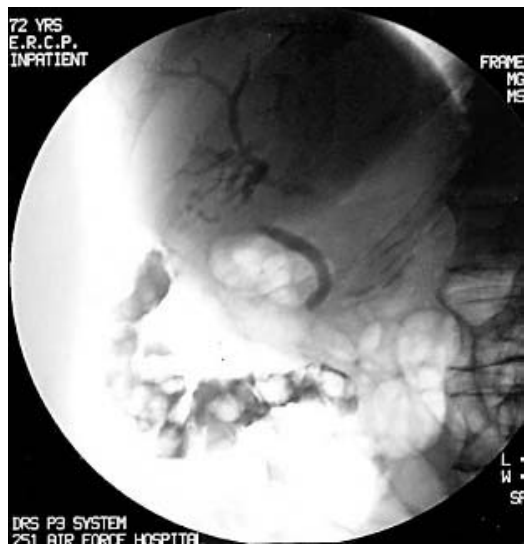

Figure 1 Visualisation of the colon shortly after cannulation of the common bile duct and contrast medium injection during ERCP. holecystocolic fistulas comprise between $10 \%$ and $20 \%$ of all biliary intestinal fistulas. In the majority of cases they are a sequel of cholecystitis but are reported to complicate only $0.13 \%$ of cases. ${ }^{1}$

A 72 year old man was admitted in our hospital for evaluation of unexplained pneumobilia demonstrated on a routine ultrasound examination of the abdomen. The patient admitted that in previous years he had recurrent episodes of biliary-type pain accompanied by low grade fever, but in the previous nine months he had been free of symptoms from the biliary tract. Barium enema was normal and blood examination showed no abnormalities. Endoscopic retrograde cholangiopancreatography (ERCP) revealed a cholecystocolic fistula (fig 1). The patient underwent cholecystectomy, excision of the fistula, bile duct exploration, and intraoperative cholangiography.

In most patients with cholecystocolic fistula, a long history of biliary tract disease is obtainable. A sequence of events occur in acute obstructive cholecystitis, resulting in the formation of the fistula. ${ }^{2}$ During these attacks, the adjacent serosal surface becomes inflamed and adherent to the gallbladder. The ischaemic area in the wall of the gallbladder becomes gangrenous, and the increased pressure within results in its contents penetrating its own necrotic wall at first and then the wall of the adjacent viscus, forming a cholecystocolic fistula. ${ }^{2}$ Recurrent episodes of jaundice and cholangitis along with small amounts of air seen within the biliary tree should raise the possibility of a cholecystocolic fistula. The most useful techniques for diagnosis are plain film of the abdomen, barium studies, and biliary scintigraphy. ERCP can identify cholecystocolic fistulas by visualisation of the colon after injection of contrast medium in the common bile duct. The recommended treatment for these fistulas is cholecystectomy, excision of the fistula, common bile duct exploration, and intraoperative cholangiography.

Although diagnosis of cholecystocolic fistula is rarely suspected clinically, it should be considered in elderly patients with unexplained biliary pneumobilia or unexplained persistent diarrhoea. ERCP can be helpful in establishing diagnosis, especially if barium studies are negative.

D Arvanitidis, G K Anagnostopoulos, S Tsiakos, G Margantinis, P Kostopoulos Gastroenterology Department, 251 Hellenic Air Force and Veterans General Hospital, Athens, Greece

Correspondence to: Dr George K Anagnostopoulos, 34 Dimokritou str, 15343, Agia Paraskevi, Athens, Greece; gkanagnostopoulos@yahoo.gr

\section{REFERENCES}

1 Hession PR, Rawlinson J, Hall JR, et al. The clinical and radiologic features of cholecystocolic fistulae. Br J Radiol 1996;69:804-9.

2 Glenn F, Reed C, Grafe W. Biliary enteric fistula. Surg Gynecol Obstet 1981;153:527-31. 